\title{
Surface Modification of Carbon Fiber by using Electro-oxidation and -reduction Sequential Procedure
}

\author{
Ryuhei Suzuki, Manabu Ishifune, ${ }^{*}$ Yasuo Mima, and Kumao UchIDA
}

\begin{abstract}
Department of Applied Chemistry, Faculty of Science and Engineering, Kinki University (3-4-1 Kowakae, HigashiOsaka, Osaka 5778502, Japan)
\end{abstract}

Received September 2, 2005 ; Accepted November 9, 2005

\begin{abstract}
A new method for the surface modification of carbon fiber by using electro-oxidation and -reduction sequential procedure has been exploited. The introduction of hydroxyl groups on carbon fiber was attained by the electrooxidation of the $\mathrm{NO}_{3}$ anion containing electrolyte using the carbon fiber as an anode, and the anodically introduced hydroxyl groups were successively transferred to the alkoxy groups by the electroreduction in the presence of alkyl halides using the oxidized carbon fiber as a cathode. The functional groups introduced on the carbon fiber were estimated by the X-ray photoelectron spectroscopy, the observation of the hydrophilicity of the carbon fibers, and also by using the carbon fibers as cathodes for the electroreduction of acetophenone (1). The diastereoselectivity of the reduced product, 2,3-diphenyl-2,3-butanediol (2), in the electroreduction of $\mathbf{1}$ indicated the interaction between the electrogenerated radical anion species of $\mathbf{1}$ with the hydroxyl groups on the carbon fiber surface, and the $d l /$ meso ratio was found to increase with an increase in the content of the hydroxyl groups on the carbon fibers. The sequential modification method for carbon fibers in one-pot was successfully performed by using the $\mathrm{MeCN}-\mathrm{H}_{2} \mathrm{O}(3: 1)$ mixed solvent containing the mixed supporting electrolytes $\mathrm{Bu}_{4} \mathrm{NNO}_{3}-\mathrm{Bu}_{4} \mathrm{NClO}_{4}(1: 1)$ and alternating the polarity of the electrodes to give the carbon fibers having high content of hydroxyl or alkoxy groups.
\end{abstract}

Key Words : Carbon Fiber, Surface Modification , Sequential Treatment, Acetophenone

\section{Introduction}

The surface modification of carbon fibers provided not only new surface structure which influences their physical property but also new function in the use for the electrochemical reaction as electrodes., 2) The modification of carbon fibers has been well studied and several practical methods have been already established. ${ }^{3-17)}$ The surface oxidation of the carbon fiber are usually required $^{3-12)}$ since the carbon fiber surface is originally hydrophobic and less reactive to the reagents for the introduction of the functional molecules on the carbon fiber. We have already achieved the introduction of hydroxyl groups on the carbon fiber surface using $\mathrm{NO}_{3}$ radicals generated by the electrooxidation of $\mathrm{NO}_{3}$ anions. ${ }^{18)}$ More recently we have also reported the electroreductive modification method in which the anodically introduced hydroxyl groups on the carbon fiber react with the added electrophiles to form the ether bondings under the cathodic reaction conditions. ${ }^{19)}$ Several functional molecules such as $\beta$-cyclodextrin were successfully fixed on the carbon fiber, however, the content of the introduced functional molecules was not enough high to show remarkable effects of the functional molecules when the resulting carbon fibers were used as the modified electrodes. In our modification method the amount of the introduced functional molecules on the carbon fiber depends on the amount of hydroxyl groups introduced in the first anodic oxidation step. However the control of the anodic oxidation of the carbon fiber surface is not always easy and the over-oxidation often brings undesired effect on the resulting carbon fiber. It was reported that excess treatment of carbon fibers under the conditions of plasma oxidation resulted in the further oxidation of the acidic functional groups that were introduced by the first oxidation of the carbon fiber surface. ${ }^{7)}$ The similar phenomenon was also observed in the electrochemical method.8) In this study we have investigated the correlation between the supplied electricity and the content of the hydroxyl groups on the carbon fibers, and performed successively the electrooxidation and electroreductive modification of carbon fibers to afford the modified carbon fibers having high content of alkoxy groups without over-oxidation. The surface character of carbon fibers were evaluated by comparing their hydrophilicity and performance as cathodes in the electroreduction of acetophenone. ${ }^{20-23)}$ Moreover, the electrolyte was optimized for the sequential procedure of the electrooxidation and the electroreductive modification of carbon fibers in one-pot by alternating the polarity of the electrodes.

\section{Experimental}

\section{1 Measurement}

The constant electrocurrent was supplied with a Takasago GP-050-2 regulated DC power supply. X-ray photoelectron spectroscopy (XPS) measurements were acquired using a Shimadzu ESCA 3200 with a Mg X-ray source under vacuum of $10^{-5}-10^{-7} \mathrm{mmHg}$. IR spectra were obtained on a Jasco FT-IR-470 Plus spectrometer. ${ }^{1} \mathrm{H}$ NMR spectra were measured on a Varian OXFORD NMR 300 (300 MHz). FT-NMR spectrometer and the chemical shift values $(\delta)$ were expressed in ppm down- 
field from the internal TMS standard.

\section{2 Materials}

Carbon fiber (felt type) was washed with acetone and dried in vacuo for $1 \mathrm{~h}$ just before use. Acetophenone was distilled in vacuo $\left(59^{\circ} \mathrm{C} / 25 \mathrm{mmHg}\right)$ under $\mathrm{Ar}$ atmosphere. $\mathrm{Et}_{4} \mathrm{NOT}$ s was prepared from ethyl tosylate with triethylamine in ethanol and purified by the recrystallization from acetone. $N, N$-Dimethylformamide (DMF) was distilled to remove water as benzene azeotrope and purified by distillation $\left(77^{\circ} \mathrm{C} / 50 \mathrm{mmHg}\right)$ under $\mathrm{Ar}$ atmosphere. Lithium nitrate $\left(\mathrm{LiNO}_{3}\right)$, tetrabutylammonium perchlorate $\left(\mathrm{Bu}_{4} \mathrm{NClO}_{4}\right)$, tetrabutylammonium nitrate $\left(\mathrm{Bu}_{4} \mathrm{NNO}_{3}\right)$, acetonitrile $(\mathrm{MeCN})$, distilled water $\left(\mathrm{H}_{2} \mathrm{O}\right)$, 1-bromobutane, dimethylsulfoxide (DMSO), hexanoic anhydride, lithium aluminum hydride (LAH) and the other materials were commercially available and used without further purification.

\section{3. 1 Electrooxidation of the untreated carbon} fiber A solution of $\mathrm{LiNO}_{3}(5 \mathrm{mmol})$ as a supporting electrolyte in the mixed solvent $\left(\mathrm{MeCN}: \mathrm{H}_{2} \mathrm{O}=10: 1,55\right.$ $\mathrm{mL}$ ) was put into an undivided electrolysis cell equipped with a carbon fiber anode $(30 \times 10 \times 7 \mathrm{~mm})$ and a $\mathrm{Pt}$ $(20 \times 20 \mathrm{~mm})$ cathode. The electrooxidation was carried out under the conditions of constant current $(200 \mathrm{~mA})$ with cooling by an ice bath. After $3 \mathrm{~F} / \mathrm{mol}$ of electricity based on the supporting electrolyte was passed, the carbon fiber anode was placed on a Soxlet type extractor and washed with running water for $1 \mathrm{~h}$ followed by acetone for $1 \mathrm{~h}$, and then dried in vacuo for $1 \mathrm{~h}$.

2. 3. 2 Electroreductive modification of the oxidized carbon fiber with 1-bromobutane A solution of 1bromobutane $(5 \mathrm{mmol})$ as an electrophile and $\mathrm{Bu}_{4} \mathrm{NClO}_{4}$ ( $5 \mathrm{mmol}$ ) as a supporting electrolyte in DMF $(30 \mathrm{~mL})$ as solvent was put into an undivided electrolysis cell equipped with a carbon fiber cathode $(30 \times 10 \times 7 \mathrm{~mm})$ and a Pt $(20 \times 20 \mathrm{~mm})$ anode. The electroreduction was carried out under the conditions of constant current (200 $\mathrm{mA}$ ) with cooling by an ice bath. After $4 \mathrm{~F} / \mathrm{mol}$ electricity based on 1-bromobutane was passed, the carbon fiber cathode was placed on a Soxlet type extractor and washed with running water for $1 \mathrm{~h}$ followed by acetone for $1 \mathrm{~h}$, and then dried in vacuo for $1 \mathrm{~h}$.

2. 3. 3 Electroreduction of acetophenone by using the electrochemically treated carbon fiber electrode A solution of acetophenone (1) $(10 \mathrm{mmol})$ in a mixed solvent $\left(\mathrm{MeCN}: \mathrm{H}_{2} \mathrm{O}=3: 1,60 \mathrm{~mL}\right.$ ) in the presence of $\mathrm{Et}_{4} \mathrm{NOTs}$ (5 mmol) as a supporting electrolyte was put into an undivided electrolysis cell equipped with the modified carbon fiber $(30 \times 10 \times 7 \mathrm{~mm})$ anode and Pt $(20 \times 20$ $\mathrm{mm}$ ) cathode. The electroreduction was carried out under the conditions of constant current (200 mA) with cooling by an ice bath. After $1 \mathrm{~F} / \mathrm{mol}$ of electricity based on acetophenone was passed, the reaction mixture was extracted with diethylether $(50 \mathrm{~mL} \times 3)$ and washed with saturated $\mathrm{NaClaq}$ and saturated $\mathrm{NaHCO}_{3} a q$. The combined organic layers were dried over anhydrous $\mathrm{MgSO}_{4}$ and concentrated. The crude product was purified by a silica gel column chromatography (hexane : ethyl acetate $=10: 1$ ) to afford 2,3-diphenyl-2, 3-butanediol (2) as the coupling products and 1-phenylethanol (3).
The products ( 2 and 3 ) and $d l /$ meso $(2 \mathrm{a} / 2 \mathrm{~b})$ ratio of diol 2 were determined by ${ }^{1} \mathrm{H}$ NMR according to the methods outlined in Refs. ${ }^{24,25)}$

2,3-Diphenyl-2,3-butanediol (2) : IR ( $\mathrm{KBr}$ ) 3495, 1447, 1141, 1064, 764, $702 \mathrm{~cm}^{-1} ;{ }^{1} \mathrm{H} \mathrm{NMR}\left(\mathrm{CDCl}_{3}\right) \delta 1.50$ (s, $6 \mathrm{H}$, $d l$-isomer), 1.60 (s, 6H, meso-isomer), 2.50 (br, $2 \mathrm{H}), 7.15-7.30$ (m, 10H).

1-Phenylethanol (3) : IR (KBr) 3666, 3072, 3036, 2939, 2885, 1494, 1448, 1384, 1043, 740, $698 \mathrm{~cm}^{-1}$; ${ }^{1} \mathrm{H}$ NMR $\left(\mathrm{CDCl}_{3}\right) \delta 1.50(\mathrm{~d}, 3 \mathrm{H}, J=4.0 \mathrm{~Hz}), 4.84-4.96(\mathrm{q}, 1 \mathrm{H}, J=4.0 \mathrm{~Hz})$, 7.25-7.40 (m, 5H).

2. 3. 4 Reduction of modified carbon fiber by using LAH The modified carbon fiber $(30 \times 10 \times 7 \mathrm{~mm})$ was put into a solution of LAH $(5 \mathrm{mmol})$ in THF $(50 \mathrm{~mL})$. After stirring for $24 \mathrm{~h}$ under Ar atmosphere at room temperature, the resulting carbon fiber was placed on a Soxlet type extractor and washed with running water for $1 \mathrm{~h}$ followed by acetone for $1 \mathrm{~h}$, and then dried in vacuo for $1 \mathrm{~h}$.

\section{Results and Discussion}

3. 1 Hydrophilicity of electrochemically oxidized carbon fibers We have reported in the previous studies $^{18,19)}$ that the phenolic hydroxyl groups are introduced on carbon fiber by the electrooxidation of the $\mathrm{LiNO}_{3}$ containing electrolyte using the carbon fiber as an anode. The amount of hydroxyl groups on the carbon fiber introduced under these anodic oxidation conditions depended on the supplied electricity, however, the increase of the electricity did not increase linearly the amount of the hydroxyl groups. The introduction extent of hydroxyl groups on the carbon fibers obtained under the conditions of several supplied electricities was evaluated by the observation of hydrophilicity (Scheme 1, Table 1). Because the felt type CF surface was too rough to measure its contact angle, the hydrophilicity of resulting $\mathrm{CF}$ was determined by the rapidness of the absorption of a drop of water.

The untreated carbon fiber (CF) showed hydrophobic character, and the carbon fiber was still hydrophobic after $100 \mathrm{C}$ of supplied electricity was passed (entries 1, 2). On the other hand, after more than $200 \mathrm{C}$ of electricity was passed, the resulting carbon fibers began to show the hydrophilicity, and the hydrophilicity was confirmed to increase with an increase of the supplied electricity (entries 3-7). The increase of the hydrophilicity corresponds to the contents of the hydroxyl groups introduced on the carbon fibers, and it is supported by the C 1s spectra that the peaks of the resulting carbon fibers attributed to the phenolic hydroxyl groups. The $\mathrm{O} / \mathrm{C}$

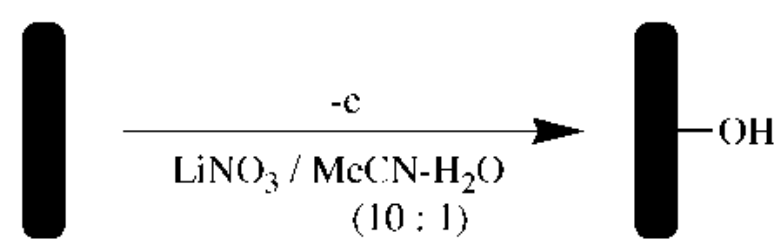

Untreated CF

CF-ox.

Scheme 1 Electrooxdation of untreated CF. 
Table 1 Electrooxidation ${ }^{\text {a) }}$ of untreated carbon fiber.

\begin{tabular}{ccl}
\hline Entry & Supplied electricity $(\mathrm{C})$ & $\begin{array}{l}\text { Hydrophilicity of } \\
\text { resulting CF }\end{array}$ \\
\hline 1 & 0 & Hydrophobic $^{\mathrm{c})}$ \\
2 & 100 & Hydrophobic $^{\mathrm{c})}$ \\
3 & 200 & Paritially hydrophilic $^{\mathrm{d})}$ \\
4 & $500\left(1 \mathrm{~F} / \mathrm{mol}^{\mathrm{b})}\right)$ & Less-hydrophilic $^{\mathrm{e}}$ \\
5 & $720\left(1.5 \mathrm{~F} / \mathrm{mol}^{\mathrm{b})}\right)$ & Hydrophilic $\left.^{\mathrm{f}}\right)$ \\
6 & $1440\left(3 \mathrm{~F} / \mathrm{mol}^{\mathrm{b})}\right)$ & Hydrophilic $\left.^{\mathrm{f}}\right)$ \\
7 & $2160\left(4.5 \mathrm{~F} / \mathrm{mol}^{\mathrm{b})}\right)$ & Hydrophilic $^{\mathrm{f}}$ \\
8 & $2880\left(6 \mathrm{~F} / \mathrm{mol}^{\mathrm{b})}\right)$ & Less-hydrophilic $^{\mathrm{e})}$ \\
\hline
\end{tabular}

a) The electrooxidation was carried our in a soulution of $\mathrm{LiNO}_{3}$ (5 mmol) in $\mathrm{MeCN}-\mathrm{H}_{2} \mathrm{O}(10: 1)(55 \mathrm{~mL})$. b) Approximately based on $\mathrm{LiNO}_{3}$. ${ }^{\text {c) }}$ Both faces of carbon fiber surface shed a drop of water. ${ }^{\text {d) }}$ Both faces of carbon fiber surface absorbed a

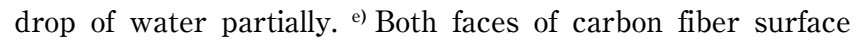
absorbed a drop of water. ${ }^{\mathrm{f}}$ Both faces of carbon fiber surface absorbed a drop of water rapidly.

strength of CF-ox. with $3 \mathrm{~F} / \mathrm{mol}$ electricity (entry 6) was determined to be $43.3 \%$ which was higher than that of the untreated $\mathrm{CF}(11.8 \%)$ or the chemically oxidized $\mathrm{CF}$ by $\mathrm{K}_{2} \mathrm{Cr}_{2} \mathrm{O}_{7}$ in $\mathrm{H}_{2} \mathrm{SO}_{4}(26.8 \%)$. However, more than 2880 $\mathrm{C}$ of supplied electricity $\left(6 \mathrm{~F} / \mathrm{mol}\right.$ based on $\left.\mathrm{LiNO}_{3}\right)$ was found to give a less hydrophilic surface of the carbon fiber (entry 8). It is probably due to the over-oxidation, that is, the introduced hydroxyl groups seems to be further oxidized to other substituents and structures such as carboxylic acid and quinone structure. The surface study of the resulting carbon fibers by the XPS, in which the peaks of the carbonyl groups at $288.6 \mathrm{eV}$ were observed, also supported this concept.

\section{2 Electroreduction of acetophenone by using the oxidized carbon fibers}

The content of hydroxyl groups has been also evaluated by using anodically oxidized CFs as cathodes in the electroreduction of acetophenone (1) (Scheme 2, Table 2). Under the conditions using $\mathrm{Et}_{4} \mathrm{NOT}$ s as a supporting electrolyte and the $\mathrm{MeCN}-\mathrm{H}_{2} \mathrm{O}$ mixed solvent, only diol 2 was obtained in $c a .50 \%$ conversion $(50 \%$ of 1 was recovered) and 1-phenylethanol (3) was not produced. The $d l / m e s o$ ratio of diol 2 in the electroreduction using 1 $\mathrm{F} /$ mol (based on $\mathrm{LiNO}_{3}$ ) oxidized carbon fiber (CF-ox.) was increased to 4.3 from 3.0, the ratio observed in the electroreduction using the untreated CF (entries 1,2). This diastereoselectivity was explainable by the mechanism shown in Fig. 1.18, 19) The anion radical species generated by the electroreduction of acetophenone (1) are protonated in the protic media to form the radical species. The protonated radical species are then fixed on the $\mathrm{CF}$ surface by the interaction based on the hydrogen bonding between the alkoxides on the carbon fiber surface with the hydroxy groups of the radicals, and $d l$-isomer favorably forms because of the steric repulsion between the phenyl groups. In the electroreduction of $\mathbf{1}$ in $\mathrm{MeCN}-\mathrm{H}_{2} \mathrm{O}(10: 1)$ as a less protic media there were not much difference in the diastereoselectivity of 2 . The $d l / m e s o$ ratio of 2 using the untreated $\mathrm{CF}$ was 2.5 (yield $22 \%$ ), while the $d l / m e s o$ ratio of 2 using the untreated $\mathrm{CF}$ was 2.3 (yield $23 \%$ ). The anion radical species are
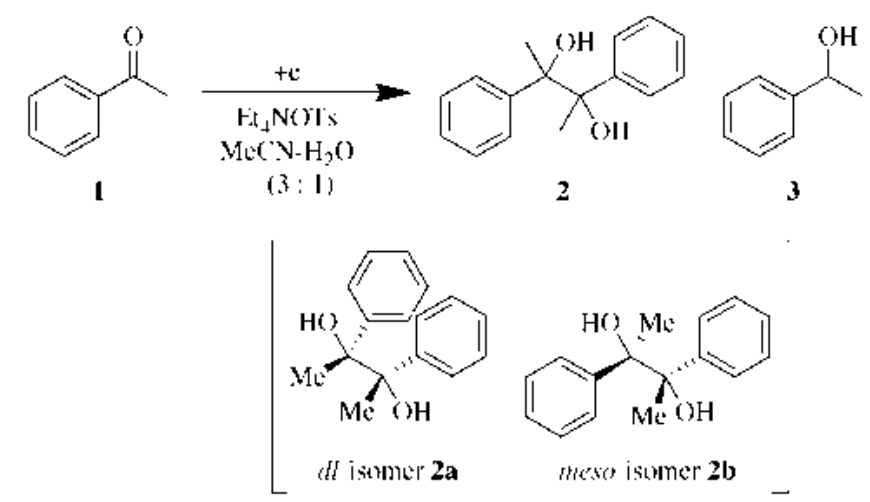

Scheme 2 Electroreduction of acetophenone.

Table 2 Electroreduction ${ }^{\text {a) }}$ of acetophenone using oxidized carbon fiber electrodes.

\begin{tabular}{cccc}
\hline Entry & $\begin{array}{c}\text { Supplied electricity } \\
\text { in electrooxidation }{ }^{\text {b) }} \\
(\mathrm{F} / \text { mol) })\end{array}$ & $\begin{array}{c}\text { Conversion of } \\
\mathbf{1} \text { to } \mathbf{2}^{\text {c }}(\%)\end{array}$ & $\begin{array}{c}d l / \text { meso } \\
(\mathbf{2 a} / \mathbf{2 b})^{\mathrm{c})}\end{array}$ \\
\hline 1 & 0 (Untreted FC) & 47 & 3.0 \\
2 & 1 & 48 & 4.3 \\
3 & 2 & 57 & 4.4 \\
4 & 3 & 45 & 5.3 \\
5 & 4 & 47 & 5.4 \\
6 & 5 & 47 & 5.1 \\
\hline
\end{tabular}

a) The electroreduction was carried our in a solution of $\mathbf{1}(10$ $\mathrm{mmol})$ in $\mathrm{MeCN}-\mathrm{H}_{2} \mathrm{O}(3: 1)(60 \mathrm{~mL})$ in the presence of $\mathrm{Et}_{4}$ NOTs $(5 \mathrm{mmol})$. The electricity was $1 \mathrm{~F} / \mathrm{mol}$ based on $\mathbf{1}$.

b) Based on $\mathrm{LiNO}_{3}$. ${ }^{\text {c) }}$ Determined by ${ }^{1} \mathrm{H} \mathrm{NMR}$ in $\mathrm{CDCl}_{3}$.

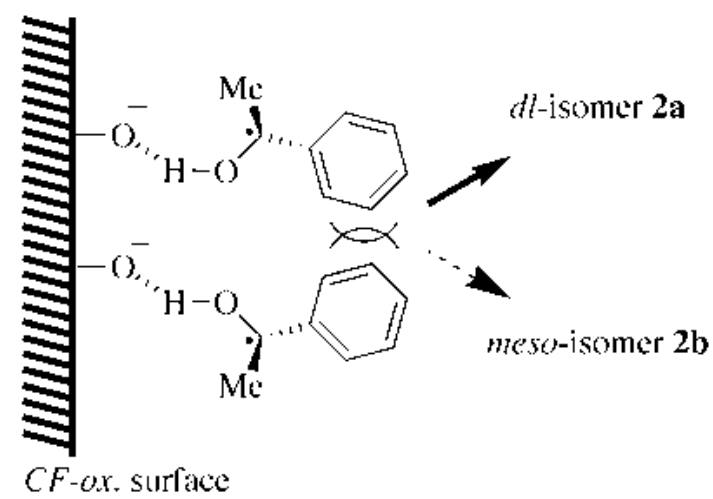

Fig. 1 Plausible interaction between acetophenone ketyl radicals with the CF-ox surface.

probably not protonated enough to interact with the alkoxides on the CFs in the less protic media. The $\mathrm{dl} / \mathrm{meso}$ ratio of 2 increases with an increase of the supplied electricity in the electrooxidation of carbon fibers (entries 3-5), and the increase of the $d l /$ meso ratio seems to correspond to the amount of the anodically introduced hydroxyl groups on the carbon fiber surface. Four $\mathrm{F} / \mathrm{mol}$ (based on $\mathrm{LiNO}_{3}$ ) of electricity for the electrooxidation of carbon fiber gave the oxidized carbon fiber that afforded highest $\mathrm{dl} / \mathrm{mes}$ ratio of $\mathbf{2}$ in the electroreductive coupling of $\mathbf{1}$, however the peak of carbonyl groups was confirmed at $288.6 \mathrm{eV}$ in the spectrum of the carbon fiber by XPS. When the supplied electricity exceeded $5 \mathrm{~F} / \mathrm{mol}$ based on $\mathrm{LiNO}_{3}$, the $d l / m e s o$ ratio of 2 decreased (entry 6). These results indicate that the undesirable over-oxi- 


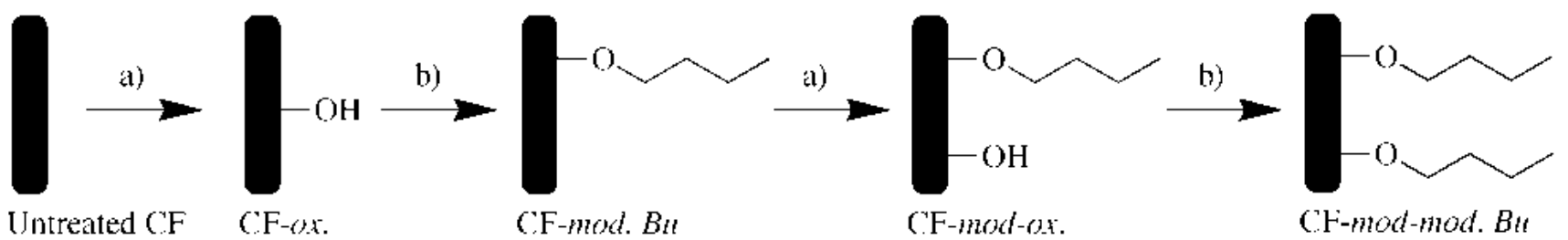

Scheme 3 Sequential surafce modification of $\mathrm{CF}$ under the conditions of a) $3 \mathrm{~F} / \mathrm{mol}$ electricity of electrooxidation in $\mathrm{MeCN}^{-\mathrm{H}_{2} \mathrm{O}}(10$ : 1) solution $(55 \mathrm{~mL})$ of $\mathrm{LiNO}_{3}(5 \mathrm{mmol})$ and b) $4 \mathrm{~F} / \mathrm{mol}$ electricity of electroreductive modification in the presence of 1-bromobutane (5 mmol) in DMF solution (50 mL) of $\mathrm{Bu}_{4} \mathrm{NClO}_{4}(5 \mathrm{mmol})$.

Table 3 Electroreduction ${ }^{\text {a) }}$ of acetophenone by using the sequentially treated carbon fiber

\begin{tabular}{|c|c|c|c|c|}
\hline Entry & Cathode & Hydrophilicity of $\mathrm{CF}$ & Conversion of 1 to $2^{\text {b) }}(\%)$ & $d l / m e s o(\mathbf{2 a} / \mathbf{2 b})^{b)}$ \\
\hline 1 & Untreated CF & Hydrophobic c) & 47 & 3.0 \\
\hline 2 & CF-ox. & Hydrophilic ${ }^{\mathrm{d})}$ & 45 & 5.3 \\
\hline 3 & CF-mod. $B u$ & Hydrophobic ${ }^{c)}$ & 49 & 3.7 \\
\hline 4 & CF-mod-ox. & Hydrophilic $^{\mathrm{d})}$ & 45 & 5.0 \\
\hline 5 & CF-mod-mod. Bu & Hydrophobic ${ }^{c)}$ & 48 & 4.2 \\
\hline
\end{tabular}

a) The electroreduction was carried out in a solution of $1(10 \mathrm{mmol})$ in $\mathrm{MeCN}-\mathrm{H}_{2} \mathrm{O}(3: 1)(30 \mathrm{~mL})$ in the presence of Et ${ }_{4} \mathrm{NOTs}(5$ mmol). The electricity was $1 \mathrm{~F} / \mathrm{mol}$ based on 1. b) Determined by ${ }^{1} \mathrm{H} \mathrm{NMR}$ in $\mathrm{CDCl}_{3}{ }^{\text {c) }}$ Both faces of carbon fiber surface shed a drop of water. ${ }^{\text {d) }}$ Both faces of carbon fiber surface absorbed a drop of water rapidly.

dation starts at $c a .4 \mathrm{~F} / \mathrm{mol}$ of electricity, and the supplied electricity was fixed to $3 \mathrm{~F} / \mathrm{mol}$ in the electrooxidation. This optimized supplied electricity shows good agreement with that determined by the observation of the hydrophilicity of the carbon fibers (Table 1 in the previous section).

\section{3 Electrochemical sequential modification of car- bon fibers}

The increase of the hydroxyl groups on the carbon fiber enhances the possibility of the over-oxidation, and the content of hydroxyl groups shows the maximum during the electrooxidation of carbon fibers. The overoxidation seems to be inevitable in the single-step electrooxidation. Then we have designed the multi-step modification of carbon fibers by using the electro-oxidation and -reduction sequential procedure (Scheme 3). Namely, the anodically introduced hydroxyl groups on the suitably oxidized carbon fiber were protected by forming the ether bonds under the electroreductive conditions. The electroreductive protection of hydroxyl groups prevents the undesirable over-oxidation and new hydroxyl groups are introduced by the further electrooxidation of the carbon fiber surface. The resulting carbon fiber is further treated under the electroreductive modification and electrooxidation repeatedly, and the content of the protected hydroxyl groups on the carbon fiber is expected to increase stepwise by the sequential procedure. The sequential introduction of butoxy groups on the carbon fiber was demonstrated by the electrooxidation and the electroreductive modification with 1-bromobutane, and the resulting carbon fibers was evaluated by the measurement of their hydrophilicity, the electrode effects in the electroreduction of acetophenone (1) (Table 3), and the surface study by XPS (Fig. 2). The change of the hydrophilicity of the resulting carbon fibers and the peak based on the phenolic hydroxyl groups at $286.8 \mathrm{eV}$ in the $\mathrm{C}$ 1s spectrum clearly indicated the introduction

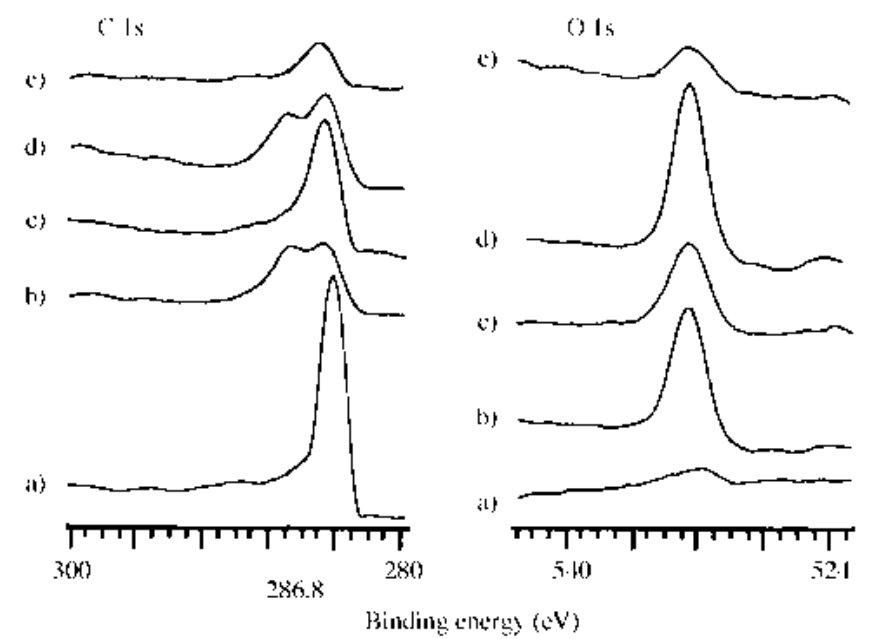

Fig. 2 Photoelectron lines of $\mathrm{C}$ 1s and $\mathrm{O}$ 1s in a) untreated $\mathrm{CF}$, b) CF-ox., c) CF-mod. Bu, d) CF-mod-ox. and e) CF-mod-mod. Bu.

of hydroxyl groups of the oxidized carbon fibers (entries 2 ,4) and alkoxylation by electroreductive modification (entries 3,5). Remarkable differences were not observed between the $\mathrm{O}$ 1s spectra of these carbon fibers. The $d l / m e s o$ ratio of the diol 2 was increased by using the carbon fiber cathode after the oxidation (entries 2,4), and decreased by using those after the alkoxylation (entries 3, 5). Especially, the hydrophilicity and the increase of the $d l / m e s o$ ratio of 2 supported the fact that the second oxidation of CF-mod. Bu proceeded without the over-oxidation to introduce new hydroxyl groups.

3. 4 Optimization of solvent system for the electrochemical modification

We have attempted the exploitation of new continuous modification method, which enables the successive introduction of the hydroxyl, and the functional groups onto the carbon fiber in one-pot only by alternation of electrodes. In order to perform the electro-oxidation and reduction sequence in one-pot, it is necessary to find a 
Table 4 Electroreductive ${ }^{\text {a) }}$ modification of oxidized carbon fiber in several solvents.

\begin{tabular}{clccl}
\hline Entry & \multicolumn{1}{c}{ Solvent } & Volume $(\mathrm{mL})$ & 1-Bromobutane (mmol) & Hydrophilicity of Resulting CF \\
\hline 1 & $\mathrm{DMF}$ & 55 & 5 & Hydrophobic $^{\text {b) }}$ \\
2 & $\mathrm{MeCN}-\mathrm{H}_{2} \mathrm{O}(10: 1)$ & 55 & 5 & Hydrophilic $^{\mathrm{c})}$ \\
3 & $\mathrm{MeCN}-\mathrm{H}_{2} \mathrm{O}(10: 1)$ & 55 & 10 & Hydrophilic $^{\mathrm{c}}$ \\
4 & $\mathrm{MeCN}-\mathrm{H}_{2} \mathrm{O}(10: 1)$ & 55 & 20 & Hydrophobic $/$ Hydrophilic $^{\mathrm{d})}$ \\
5 & $\mathrm{MeCN}-\mathrm{H}_{2} \mathrm{O}(3: 1)$ & 30 & 5 & Hydrophobic $^{\text {b) }}$ \\
\hline
\end{tabular}

a) The electroreductive modification was carried out in a solution of 1-bromobutane in solvent in the presence of $\mathrm{Bu}_{4} \mathrm{NClO}_{4}(5 \mathrm{mmol})$. The electricity was $4 \mathrm{~F} / \mathrm{mol}$ based on 1-bromobutane. ${ }^{\text {b) }}$ Both faces of carbon fiber surface shed a drop of water. ${ }^{\text {c) }}$ Both faces of carbon fiber surface absorbed a drop of water rapidly. ${ }^{\text {d) }}$ One face of carbon fiber surface shed a drop of water, while the other face was absorbed a drop of water.

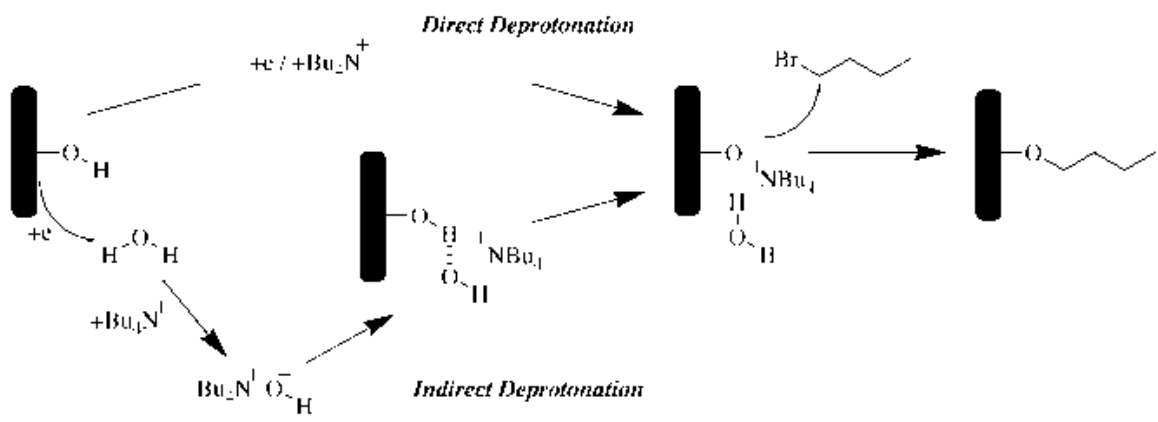

Fig 3 Plausible mechanism participating of $\mathrm{H}_{2} \mathrm{O}$ in electroreductive modification.

common electrolyte for both the electrooxidation and the electroreductive modification. The electrooxidation was usually carried out in $\mathrm{MeCN}-\mathrm{H}_{2} \mathrm{O}(10: 1)$ and the electroreductive modification, in DMF. The $\mathrm{MeCN}-\mathrm{H}_{2} \mathrm{O}$ mixed solvent systems have been tried for the electroreductive modification of the CF-ox. with 1-bromobutane (Table 4). The electroreductive modification was performed in $\mathrm{MeCN}-\mathrm{H}_{2} \mathrm{O}(10: 1)$, which is the same solvent system as the electrooxidation, with increasing the added amount of 1-bromobutane as an electrophile (entries 2-4). The hydrophilicity of the carbon fibers was, however, not changed and it indicated that the electroreductive alkoxylation did not proceed efficiently. Interestingly higher content of water was found to be effective to the electroreductive modification. The carbon fiber surface became hydrophobic by the electroreduction in $\mathrm{MeCN}-\mathrm{H}_{2} \mathrm{O}(3: 1)$ (entry 5).

The effect of the $\mathrm{H}_{2} \mathrm{O}$ containing solvents can be explained by the indirect deprotonation mechanism shown in Fig. 3, while the electroreductive modification usually proceeds in direct mechanism in anhydrous media such as DMF. The hydroxide ions are generated by the electroreduction of water, and react as an electrogenerated base with the hydroxyl groups on the carbon fiber to form the anionic species. This indirect deprotonation is probably more effective than the direct deprotonation from the hydroxyl groups on the cathode.

The electrooxidation of untreated carbon fiber in the presence of $\mathrm{LiNO}_{3}$ was also performed in several solvent system (Table 5). $\mathrm{MeCN}-\mathrm{H}_{2} \mathrm{O}(10: 1)$ was usually used in the electrooxidation, however, not effective for the electroreductive modification as mentioned above. The use of aprotic polar solvent such as DMF and DMSO, which were suitable for the electroreductive modification of carbon fibers, were also examined, however, these sol-
Table 5 Electrooxidation ${ }^{\text {a) }}$ of untreated carbon fiber in several solvents.

\begin{tabular}{|c|c|c|c|}
\hline Entry & Solvent & Volume (mL) & $\begin{array}{l}\text { Hydrophilicity } \\
\text { of Resulting CF }\end{array}$ \\
\hline 1 & 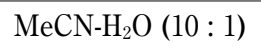 & 55 & Hydrophilic $^{\text {b) }}$ \\
\hline 2 & & & \\
\hline 3 & DMSO & 30 & $\begin{array}{l}\text { Hydrophilic / } \\
\text { Hydrophobic }^{\mathrm{d}}\end{array}$ \\
\hline 4 & $\mathrm{MeCN}_{-} \mathrm{H}_{2} \mathrm{O}(3: 1)$ & 30 & Hydrophilic ${ }^{\mathrm{b})}$ \\
\hline \multicolumn{4}{|c|}{$\begin{array}{l}\text { a) The electrooxidation was carried out in a solution of } \mathrm{LiNO}_{3}(5 \\
\text { mmol) in solvent. The electricity was } 3 \mathrm{~F} / \mathrm{mol} \text { based on } \mathrm{LiNO}_{3} \text {. b) } \\
\text { Both faces of carbon fiber surface absorbed a drop of water } \\
\text { rapidly. }{ }^{\text {c) }} \text { The electricity was passivated by the rise of terminal } \\
\text { voltage. }{ }^{\text {d) }} \text { One face of carbon fiber surface absorbed a drop of } \\
\text { water, while the other face was shed a drop of water. }\end{array}$} \\
\hline
\end{tabular}

vents were not effective for the electrooxidation of carbon fibers (entries 3, 4). Fortunately, the $\mathrm{MeCN}_{-} \mathrm{H}_{2} \mathrm{O}$ (3 : 1) mixed solvent, which was found to be effective for the electroreductive modification, was also effective for the electrooxidation of carbon fiber and the hydrophilic carbon fiber was successfully obtained (entry 4).

3. 5 Optimization of supporting electrolytes for the electrochemical modification

The supporting electrolytes were next optimized for the electro-oxidation and -reduction sequence in MeCN$\mathrm{H}_{2} \mathrm{O}(3: 1)$ (Table 6). In the electrooxidation of carbon fiber surface $\mathrm{LiNO}_{3}$ was usually used, and in the electroreductive modification, $\mathrm{Bu}_{4} \mathrm{NClO}_{4}$. Then the mixed salts of $\mathrm{LiNO}_{3}$ and $\mathrm{Bu}_{4} \mathrm{NClO}_{4}$ were examined (entry 1). The surface oxidation proceeded, successfully making the surface of carbon fiber hydrophilic, however, the successive electroreductive modification was not achieved and the hydrophobic character which should appear on 
Table 6 Optimization of supporting electrolyte system for electrooxidation and electroreductive modification.

\begin{tabular}{|c|c|c|c|}
\hline \multirow{2}{*}{ Entry } & \multirow{2}{*}{ Supporting electrolyle } & \multicolumn{2}{|c|}{ Hydrophilicity of resulting carbon fiber } \\
\hline & & Electrooxidation $^{\text {a) }}$ & Electroreductive modification ${ }^{\text {b) }}$ \\
\hline 1 & $\mathrm{LiNO}_{3}-\mathrm{Bu}_{4} \mathrm{NClO}_{4}(1: 1)$ & Hydrophilic ${ }^{c)}$ & Hydrophilic ${ }^{c)}$ \\
\hline 2 & $\mathrm{Bu}_{4} \mathrm{NNO}_{3}$ & Hydrophilic ${ }^{c)}$ & Hydrophobic / Hydrophilic ${ }^{\mathrm{d})}$ \\
\hline 3 & $\mathrm{Bu}_{4} \mathrm{NNO}_{3}-\mathrm{Bu}_{4} \mathrm{NClO}_{4}(4: 1)$ & - & Partially hydrophilic ${ }^{\mathrm{e}}$ \\
\hline 4 & $\mathrm{Bu}_{4} \mathrm{NNO}_{3}-\mathrm{Bu}_{4} \mathrm{NClO}_{4}(3: 2)$ & - & Hydrophobic / Partially hydrophilic \\
\hline 5 & $\mathrm{Bu}_{4} \mathrm{NNO}_{3}-\mathrm{Bu}_{4} \mathrm{NClO}_{4}(1: 1)$ & Hydrophilic ${ }^{c)}$ & Hydrophobic ${ }^{g)}$ \\
\hline
\end{tabular}

a) The electrooxidation was carried out in a solution of supporting electrolytes (5 mmol) in $\mathrm{MeCN}-\mathrm{H}_{2} \mathrm{O}(3: 1)(30 \mathrm{~mL})$. The electricity was $3 \mathrm{~F} / \mathrm{mol}$ based on supporting electrolytes. ${ }^{\text {b) }}$ The electroreductive modification was carried out in a solution of 1-bromobutane ( $5 \mathrm{mmol})$ in $\mathrm{MeCN}-\mathrm{H}_{2} \mathrm{O}(3: 1)(30 \mathrm{~mL})$ in the presence of supporting electrolyte $(5 \mathrm{mmol})$. The electricity was $4 \mathrm{~F} / \mathrm{mol} \mathrm{based}$ on 1 -

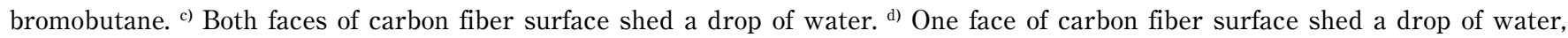
while the other side absorbed a drop of water. ${ }^{\text {e) }}$ Both faces of carbon fiber surface absorbed a drop of water partially. ${ }^{f}$ One face of carbon fiber surface shed a drop of water partially, while the other side absorbed a drop of water. ${ }^{\mathrm{g})}$ Both faces of carbon fiber surface absorbed a drop of water rapidly.

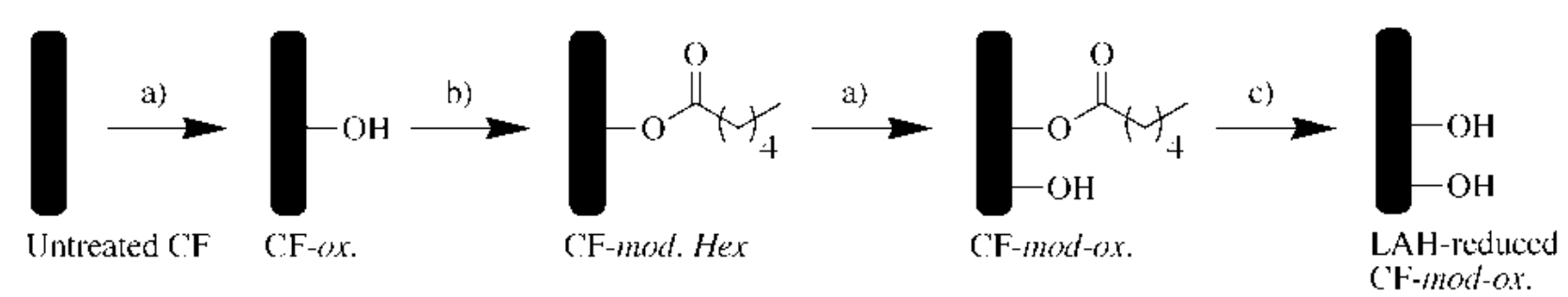

Scheme 4 Sequential surafce treatment of $\mathrm{CF}$ under the conditions on $3 \mathrm{~F} / \mathrm{mol}$ of electrooxidation in $\mathrm{MeCN}_{-} \mathrm{H}_{2} \mathrm{O}(10: 1)$ solution $(55$ $\mathrm{mL})$ of $\mathrm{LiNO}_{3}(5 \mathrm{mmol})$, b) $4 \mathrm{~F} / \mathrm{mol}$ electricty of electroreductive modification in the presence of hexanoic anhydride (5 mmol) in DMF solution $(50 \mathrm{~mL})$ of $\mathrm{Bu}_{4} \mathrm{NClO}_{4}(5 \mathrm{mmol})$ and c) THF solution $(50 \mathrm{~mL})$ of $\mathrm{LAH}(5 \mathrm{mmol})$.

the carbon fiber after alkoxylation of the anodically introduced hydroxyl groups was not observed. It is probably due to relatively low nucleophilicity of the alkoxide ion bearing lithium ion as a counter cation. Most of the alkoxide ions which are formed by the deprotonation of the hydroxyl groups on the CF-ox. under these electroreduction conditions have lithium ions as counter cations, and are less nucleophilic than the alkoxide ions bearing tetrabutylammonium ions. We have next tried $\mathrm{Bu}_{4} \mathrm{NNO}_{3}$ as a quaternary ammonium salt having $\mathrm{NO}_{3}$ anion (entry 2). This salt was effective for the electrooxidation of the carbon fiber surface since the resulting oxidized carbon fiber showed high hydrophilicity, but the result of the electroreductive modification of the CF-ox. by using $\mathrm{Bu}_{4} \mathrm{NNO}_{3}$ was not satisfactory. High concentration of $\mathrm{NO}_{3}$ anions in the electrolytes enhances the generation of the oxidative $\mathrm{NO}_{3}$ radicals, which probably prevent the electroreductive modification of the carbon fiber. In order to control the concentration of $\mathrm{NO}_{3}$ anions in the electrolytes, the mixed electrolytes of $\mathrm{Bu}_{4} \mathrm{NNO}_{3}$ and $\mathrm{Bu}_{4} \mathrm{NClO}_{4}$ were used and the mixed ratio was optimized (entries 3-5). Finally the mixed supporting electrolytes system of $\mathrm{Bu}_{4} \mathrm{NNO}_{3}-\mathrm{Bu}_{4} \mathrm{NClO}_{4}(1: 1)$ in the mixed solvent of $\mathrm{MeCN}-\mathrm{H}_{2} \mathrm{O}(3: 1)$ was found to be effective for both the electrooxidation of the carbon fiber surface and the successive electroreductive alkoxylation of the anodically introduced hydroxyl groups.

3. 6 Electrochemical successive one-pot modification of carbon fibers

By using the optimized electrolyte, $\mathrm{Bu}_{4} \mathrm{NNO}_{3}-\mathrm{Bu}_{4} \mathrm{NClO}_{4}$ $(1: 1)$ mixed supporting electrolytes in $\mathrm{MeCN}_{-} \mathrm{H}_{2} \mathrm{O}(3: 1)$, we have successively carried out the electrooxidation (3 $\mathrm{F} / \mathrm{mol}$ based on $\mathrm{Bu}_{4} \mathrm{NNO}_{3}$ ) of the carbon fiber surface and the electroreductive modification $(4 \mathrm{~F} / \mathrm{mol}$ based on 1-bromobutane) in the presence of 1-bromobutane as an electrophile to afford the carbon fiber modified with butoxy groups. Moreover this electro-oxidation and reduction sequence can be repeated for three times by alternating the polarity of the electrodes with the interval of $1 \mathrm{~F} / \mathrm{mol}$. After total $6 \mathrm{~F} / \mathrm{mol}$ of electricity was passed, one face of the resulting carbon fiber was hydrophobic and the other face showed the hydrophilicity. It probably indicates that the introduction of hydroxyl groups by the electrooxidation proceeds more effectively than the alkoxylation by the electroreduction. In order to confirm the increase of the content of the introduced substituents on the carbon fiber by the successive electrochemical treatment, the electroreductive transformation of the anodically introduced hydroxyl groups to the ester groups by using hexanoic anhydride as an electrophile, further electrooxidation of the protected carbon fiber, and the reduction of the introduced ester groups to hydroxyl groups by using LAH were examined (Scheme 4). The observation of hydrophilicity and the surface study by XPS of the resulting carbon fibers clearly indicated the introduction of ester groups by the electroreductive modification and the recovery of hydroxyl groups by the treatment with LAH. Additionally the electroreduction of acetophenone (1) by using the LAHreduced CF-mod-ox. as a working electrode gave the highest $\mathrm{dl} / \mathrm{meso}$ ratio (5.4) of diol 2 in our research, and this result indicated the increase of the content of the 
introduced hydroxyl groups on the carbon fiber.

\section{Conclusion}

The correlation between the supplied electricity in the electrooxidation and the relative amount of the introduced hydroxyl groups on the carbon fiber surface was investigated, and it was confirmed that the amount of hydroxyl groups on the carbon fiber increased with an increase in electricity until about $5 \mathrm{~F} / \mathrm{mol}$ based on $\mathrm{LiNO}_{3}$ but further electrooxidation resulted in the decrease of the hydroxyl groups by the over-oxidation. Then we designed the sequential surface modification process of the carbon fiber by using the electrooxidation and electroreductive modification repeatedly. By using the electro-oxidation and -reduction sequential procedure, the stepwise increase of the introduced content of the substituents on the carbon fiber surface was expected without the over-oxidation. Moreover, we have attempted the exploitation of the successive modification method of the carbon fiber in one-pot by alternating the polarity of the electrodes, and optimized the electrolyte for this purpose. In the optimized electrolyte, $\mathrm{MeCN}-\mathrm{H}_{2} \mathrm{O}$ mixed solvent $(3: 1)$ containing the mixed supporting electrolytes of $\mathrm{Bu}_{4} \mathrm{NNO}_{3}-\mathrm{Bu}_{4} \mathrm{NClO}_{4}(1: 1)$, the successive electrooxidation and electroreductive modification of the carbon fiber in one-pot was achieved to give the carbon fiber having higher content of the hydroxyl or alkoxy groups.

\section{References}

1) F. Severini. L. Formaro, M. Pegoraro, and L. Posca, Carbon, 40, 735 (2002).

2) D. De, J. D. Englehardt, and E. E. Kalu, J. Electrochem. Soc., 147, 4573 (2000) .

3) R. W. Murray, Acc. Chem. Res., 13135 (1980).

4) Y. Murakami, and Y. Hisada, T. Ozaki, and Y. Matsuda, J. Chem. Soc., Chem. Commun., 1989, 1094 .

5) P. V. Lakshminarayanan, H. Toghiani, and C. U. Pittman Jr., Carbon, 42, 2433 (2004).

6) Y. V. Basova, H. Hatori, Y. Yamada, and K. Miyashita,
Electrochem. Commun., 1, 540 (1999).

7) C. U. Pittman Jr., W. Jiang, G.-R. He, and S. D. Gardnar, Carbon, 36, 25 (1998).

8) C. U. Pittman Jr., W. Jiang, Z. R. Yue, S. Gardnar, L. Wang, H. Toghiani, and C. A. Leon y Leon, Carbon, 37, 1797 (1999).

9) J. Gulyás, E. Földes, A. Lázár, and B. Pukánszky, Composites: Part A, 32, 353 (2001).

10) J. P. Boudou, J. I. Paredes, A. Cuesta, A. MartínezAlonso, and J. M. D. Tascón, Carbon, 41, 41 (2003).

11) K. J. Hüttinger, W. P. Hoffman, and G. Krekel, J. Mater. Sci. 29, 2968 (1994).

12) For reviews ; H. Maeda, Yakugaku Zasshi, 120, 170 (2000). H. Maeda, Y. Yamauchi, and H. Ohmori, Current Topics in Anal. Chem., 2, 121 (2001).

13) F. Severini, L. Formaro, M. Pegoraro, and L. Posca, Carbon, 40735 (2002).

14) T. Osa, U. Akiba, I. Segawa, and J. M. Bobbitt, Chem. Lett., 1988, 1423.

15) T. Osa, Y. Kashiwagi, K. Mukai, A. Ohsawa, and J. B. Bobbitt, Chem. Lett., 199075.

16) Y. Kashiwagi, A. Ohsawa, T. Osa, Z. Ma, and J. B. Bobbitt, Chem. Lett., 1991581.

17) Y. Kashiwagi, H. Ono, and T. Osa, Chem. Lett., 1993257.

18) S. Kashimura, Y. Murai, Y. Tamai, R. Hirose, M. Ishifune, H. Iwase, H. Yamashita, N. Yamashita, and H. Kakegawa, Electrochim. Acta, 46, 3265 (2001).

19) M. Ishifune, R. Suzuki, Y. Mima, K. Uchida, N. Yamashita, and S. Kashimura, Electrochim. Acta, 51, 14 (2005).

20) C. Libot and D. Pletcher, Electrochem. Commun., 2, 141 (2000).

21) Y. Kodama, M. Imoto, N. Ohta, A. Kitani, and S. Ito, J. Electroanal. Chem., 507, 103 (2001).

22) N. A. Maiorova, A. A. Stepanov, M. K. Grachev, G. I. Kurochkina, and V. A. Grinberg, Russ. J. Electrochem., 40, 1074 (2004).

23) H. Takechi, M. Machida, and Y. Kanaoka, Liebigs Ann. Chem., 1986859.

24) R. D. Rieke and S.-H. Kim, J. Org. Chem. 63, 5235 (1998).

25) T. Matsue, M. Fujihira, and T. Osa, J. Electrochem. Soc. 126, 500 (1979). 